\title{
Uncovering Culture and Identity in Refugee Camps
}

\author{
Ayham Dalal \\ Department of Architecture, Technische Universität Berlin, 10623 Berlin, Germany; \\ a.dalal@campus.tu-berlin.de or ayham.dalal@live.co.uk
}

Received: 7 July 2017; Accepted: 7 August 2017; Published: 16 August 2017

Refugee camps, especially in their emergency phases, are places where everything seems to be similar, repetitive, and modular. This impression is not only due to the unified shelter unit that is usually distributed by $\mathrm{UNHCR}^{1}$ (traditionally a tent, and recently caravans, prefabs, and developed T-Shelters), but is also due to the camps' ordered layout and hierarchical plan (Figures 1-3). This generates an assumption that all refugees are the same, and a feeling of a collective identity emerges: "All of us carry water from the same water tank...all of us go to the same toilet...all of us go to the same mall....and all of us have the same visa $\left[\mathrm{WFP}^{2}\right.$ debt cards]...we are all the same ... we are all refugees"- a young man from Zaatari camp in Jordan explained. This is true, but it is definitely not the whole truth. When a villager from Daraa was asked about how he feels to be in the same camp with city dwellers, he replied, "I felt they are different... the prestige and lifestyle which they are used to does not fit in here...I thought they should be living in Amman-I am even shy to ask them what happened!". At the same time, a man from Damascus complained about the traditions of villagers from Southern Syria; "Their weddings last for weeks and they are mixed [men and women]! In Damascus, it was just one night ... women celebrate by themselves and men celebrate by themselves!"

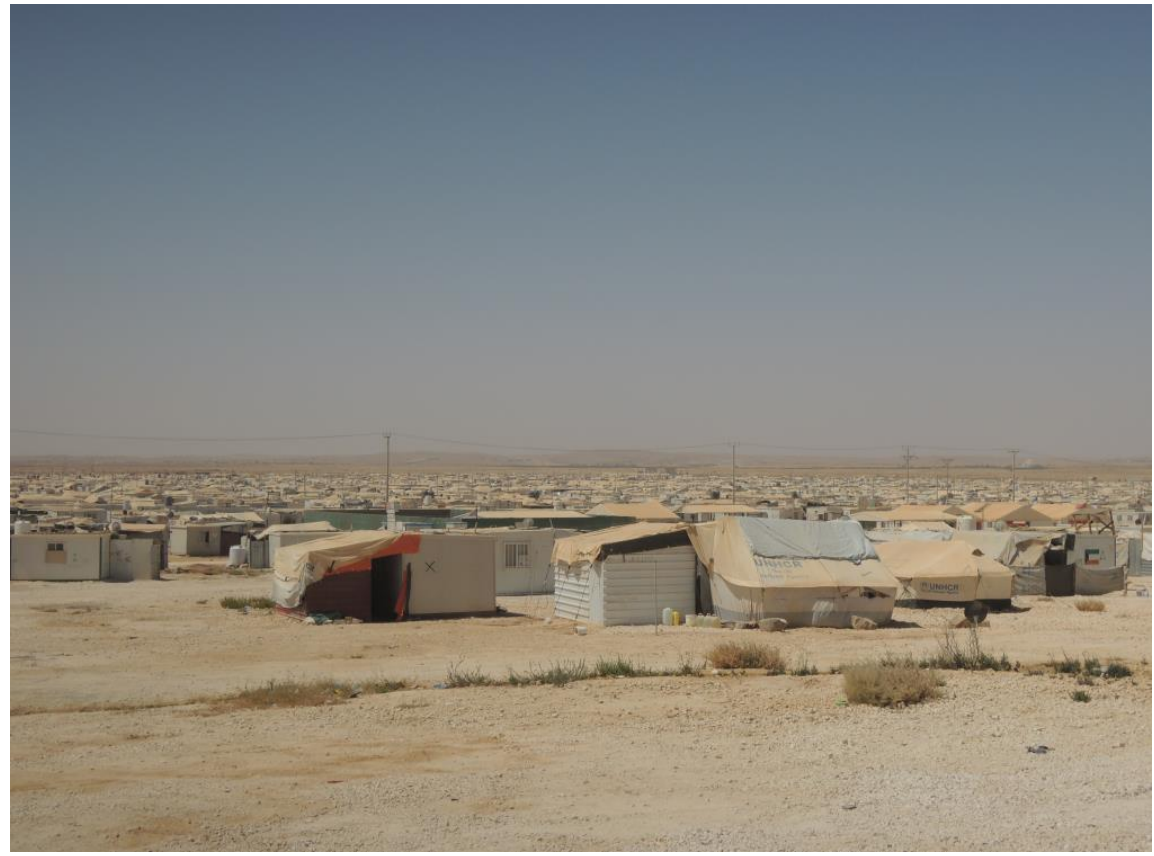

Figure 1. Zaatari Camp (Source: Author 2015).

\footnotetext{
United Nations High Commissioner for Refugees.

World Food Program.
} 


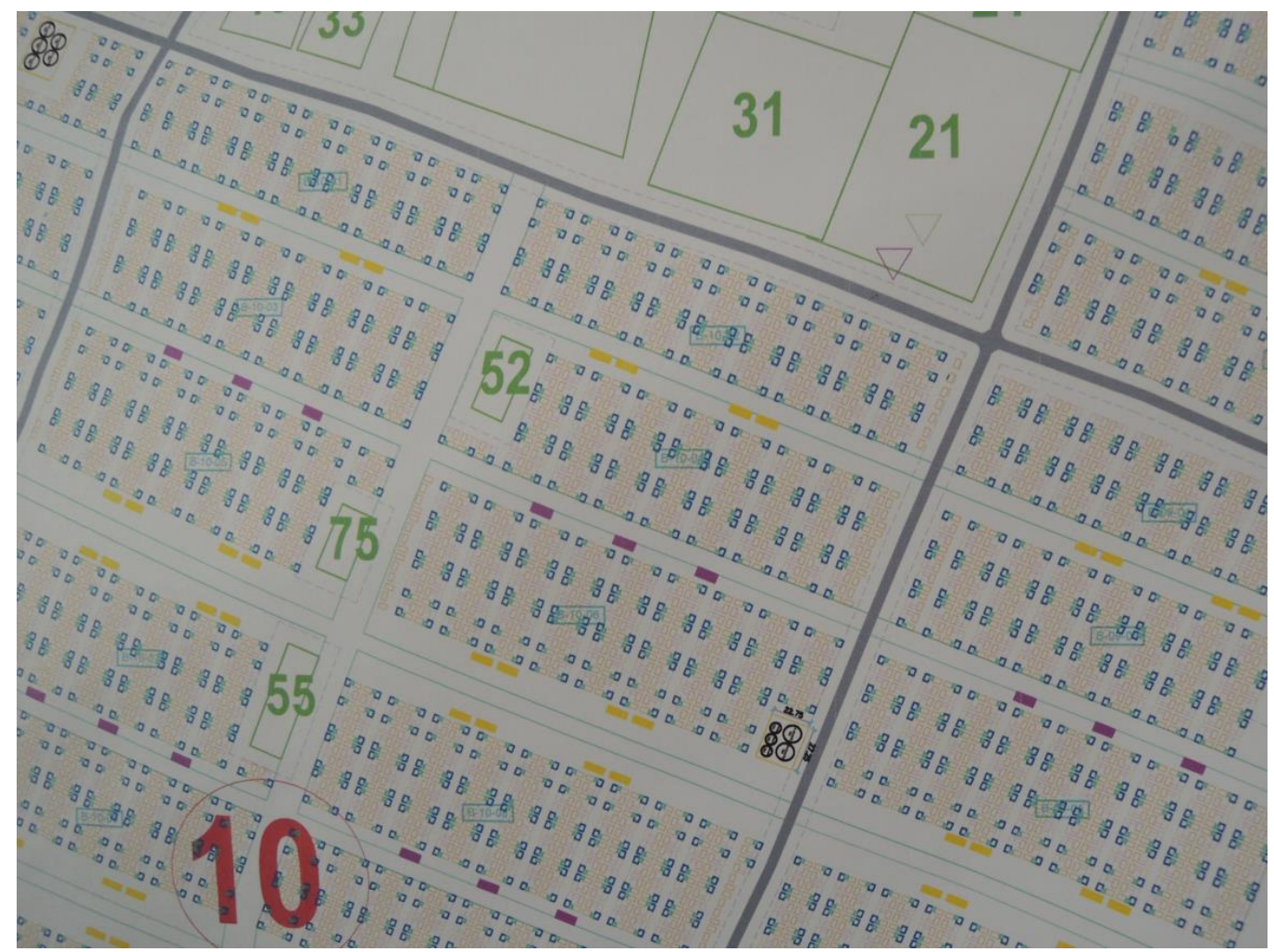

Figure 2. Zaatari camp as planned by UNHCR (Source: Author, 2015).

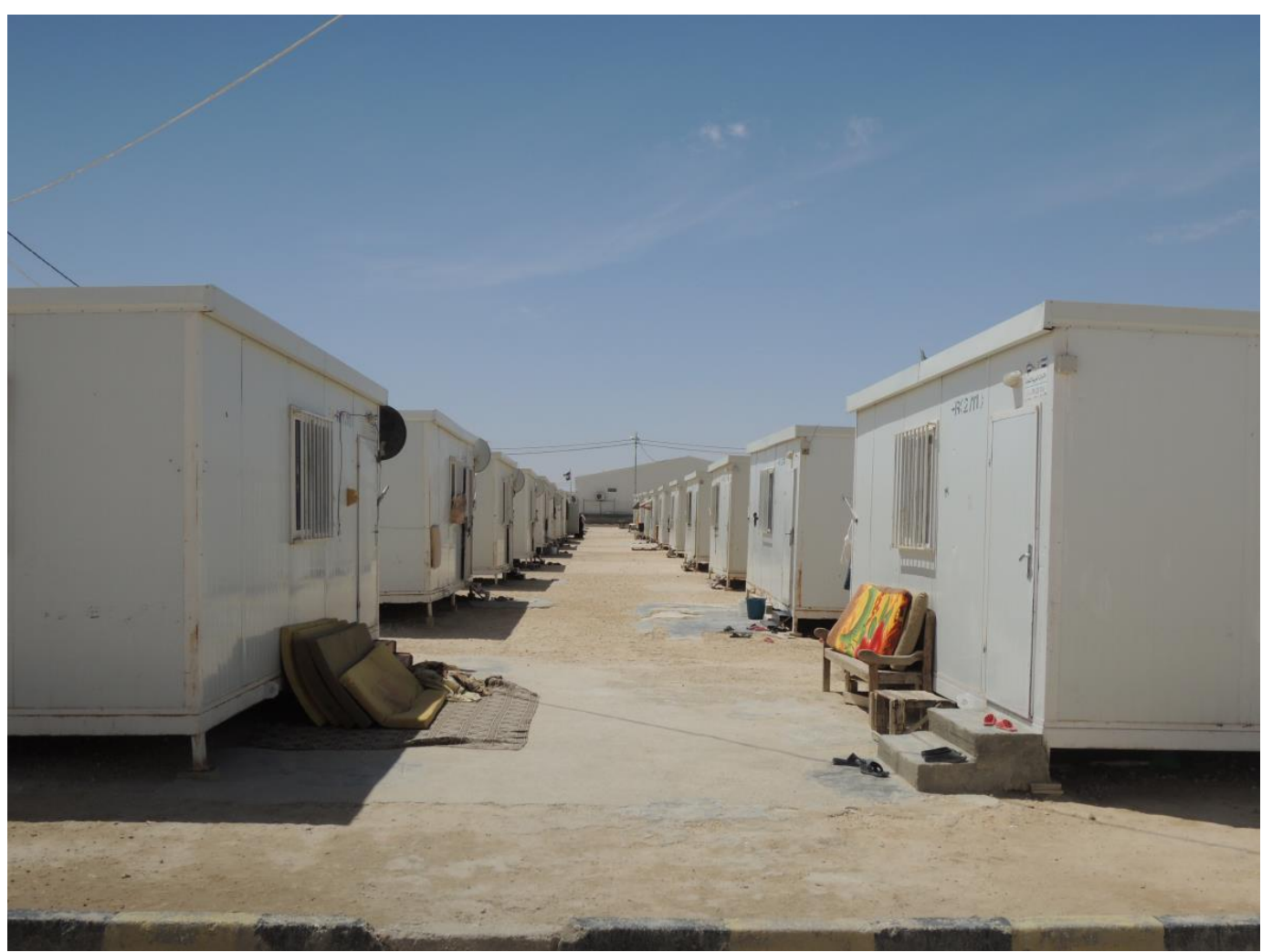

Figure 3. The Emirati-Jordanian Camp in Jordan (Source: Author, 2016). 
These cultural differences appear in the building and housing traditions within the unified shelters. For instance, another young man who used to live in Damascus furnished his caravan with sofas and a table similar to salons you find in cities, whereas the houses of the Bedouins (nomads) from Daraa and Homs could be identified by their extensive use of tent sheets to demarcate space and construct the dwelling. Yet, these traditions and cultures mix together. In fact, the camp may present itself as an opportunity that would never have happened for some in Syria. A young man from Zaatari explained about how people from his village changed; "They got mixed with new societies, got introduced to new people, saw how they used to live....back in the village they were closed ... now they expanded their horizons." This observation appears to be valid in an economic sense as well. While many families suffer from the lack of economic opportunities in camps like Zaatari and Azraq in Jordan, some are very well-off. A man sitting inside a house with a small rundown fountain, no different from the houses next to it (Figure 4), explained, "We have a salon for brides attached to our house ... we had six young girls working for us ... and sometimes we prepared 16 brides a day!" This gives an idea of the different levels of income inside the camp.

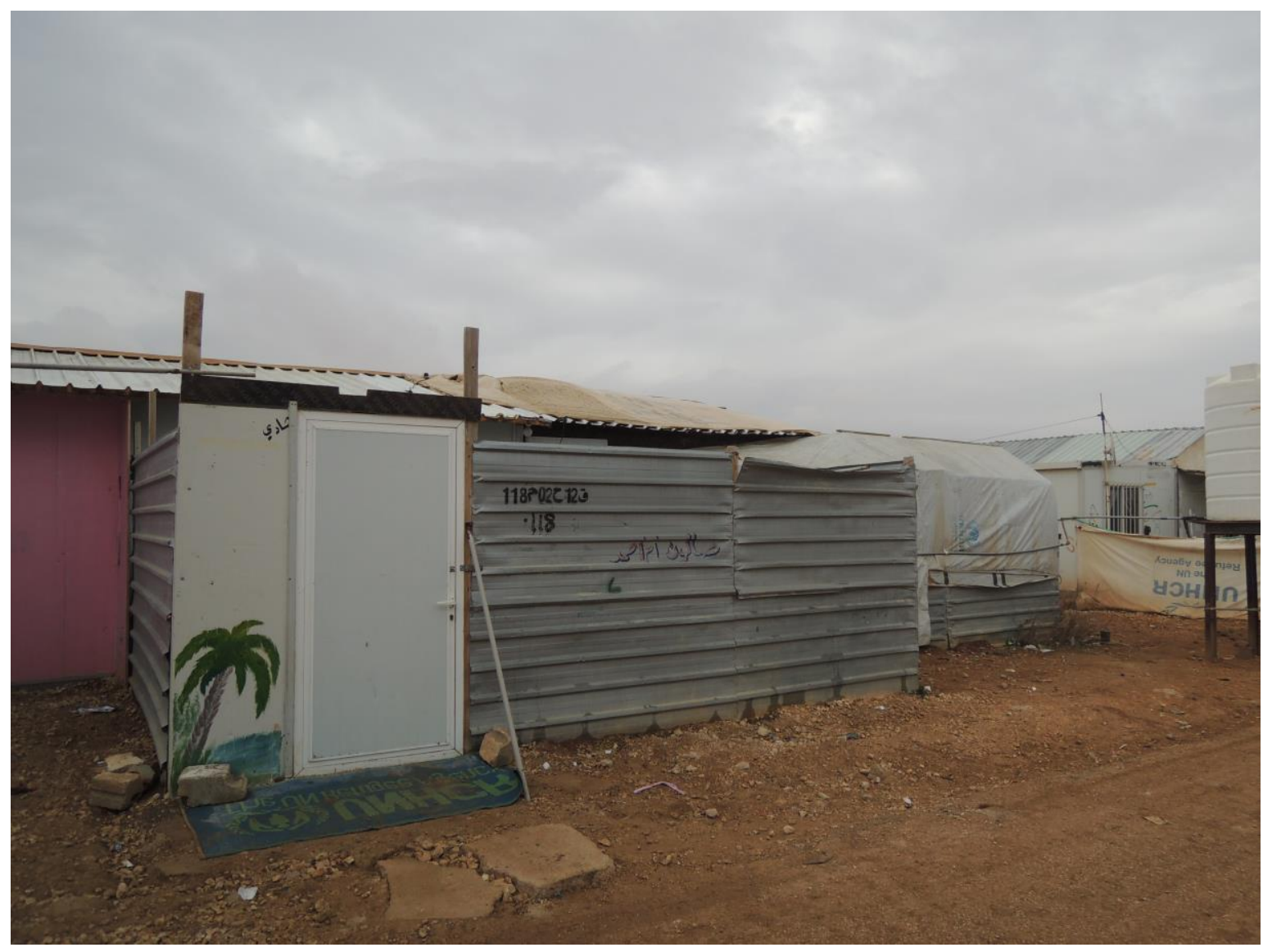

Figure 4. Salon Um-Ahmad for brides with a pink door attached to their house (Source: Author, 2017). 
Despite the initial visual/systematic homogeneity, the camp is a site for cultural diversity, contestation, and hybridization. Coming from different regions, backgrounds, traditions, urban settings (villagers, city dwellers, nomads), and economic conditions (rich, middle-class, and poor), a refugee camp resembles a colorful mosaic that is suddenly painted with white, over which the big turquoise signage of UNHCR has been placed. These dynamics, mosaics, and colors need to be uncovered again. ${ }^{3}$

Conflicts of Interest: The author declares no conflict of interest.

(C) 2017 by the author. Licensee MDPI, Basel, Switzerland. This article is an open access article distributed under the terms and conditions of the Creative Commons Attribution (CC BY) license (http://creativecommons.org/licenses/by/4.0/).

3 This text is based on the fieldwork notes of the author, conducted between November 2016 and April 2017 in Zaatari camp as part of his Ph.D. research: "Understanding the Morphology of Zaatari Camp: The Role of Culture, Representations of Home and the Social Structuring of Space" at TU Berlin. Taking an ethnographic approach, the study looks at 'Home' as a microcosm to understand the social structuring of the camp's space and reveal the different factors related to it. Additionally to the previously mentioned fieldwork, the study builds on the author's experience and engagement in Syrian and Palestinian camps in Jordan since 2014 as a researcher, consultant and tutor for several workshops and studies. 